\title{
UMA FUNDAMENTAÇÃO GEOGRÁFICA AO PAISAGISMO REGIONAL
}

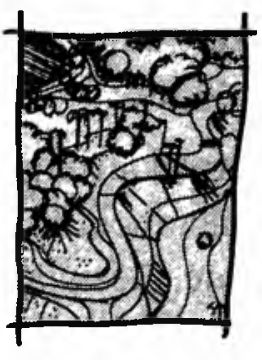

prontas para receber qualquer projeto ou plano.

MARIA ANGELA FAGGIN PEREIRA LEITE

Um dos aspectos mais importantes a ser considerado quando estudamos o uso e a conservação de um território, é a sua organização como paisagem. As paisagens revelam-se diferentemente a cada observador, de acordo com diferentes graus de percepção e interesse. Mas, de maneira geral, para o planejador físico, as paisagens são eternas bases vivas,

De acordo com Laurie ${ }^{1}$ o território se torna paisagem quando é descrito ou visto através de suas características fisiográficas e ambientais. A paisagem varia de acordo com essas características e, também, de acordo com o impacto histórico do homem sobre ela. Portanto, a paisagem é um reflexo dinâmico dos sistemas natural e social.

Para Hackett ${ }^{2}$, o papel do planejador paisagístico é o de situar e unir vários tipos de uso do solo, por meio de um processo baseado no conhecimento técnico da fisiologia da paisagem enoentendimento estético de sua fisionomia. Oresultadodesseprocessoseria a obtenção de um novo estágio de organização da paisagem.

Crowe ${ }^{3}$ é de opinião que planejamento paisagístico é um conceito mais amplo do que planejamento de usodo solo, porque inclui tanto o usoquanto a fisionomiada paisagem. Para ela, a função do paisagistaé a de dirigir o intrincado misturar de habitatse funções, separando o que é incompatível, reconciliando usos diversos e, principalmente, relacionando cada uso específico à totalidade da paisagem.

Já McHarg ${ }^{4}$, questiona as intervençõese mudanças operadas pelo homem na paisagem. Para ele, o homem, como parte da natureza, é solicitado a ser criativo no processo de evolução da paisagem e as mudanças obtidas pela sua intervenção devem, necessariamente, ser enquadradas nas leis da evolução natural. Seu sistema de planejamento paisagístico está baseado na proposição de que a natureza apresenta processos e valores que oferecem oportunidades e restrições ao uso humano.

Por outro lado, Gregotti ${ }^{5}$, considera que a expansão espacial e a aceleração temporal das modificações do ambiente, que atualmente se verificam em todas as escalas, têm obrigado os profissionais que trabalham com intervenções na paisagem, a recorrer,com freqüência, à ajuda dos estudos interdisciplinares, como forma de subsidiar a forma- 
lização das transformações territoriais, cujos efeitos nem sempre podem ser controlados. Isto porque, entre outros fatores, a essa expansão espacial e aceleração temporal dos processos de modificação da paisigem, não corresponde, ainda, uma instrumentação adequada e específica ao nível das técnicas formais de intervenção em grande escala. Dessa forma, as propostas elaboradas são avaliações independentes, mais do que projetos capazes de servir-se dos fatores que determinam a forma das paisagens em grande escala.

Essas citações, que poderiam ser reforçadas por dezenas deoutrosautores, revelam uma preocupação acentuada com anecessidade de investigar a tolerância ou intolerânciados diversosambientesao uso pelo homem em geral e a alguns usosespecialmente. Oestudo dạs relações entre os elementos de uma paisagem, tem por objetivo principal a obtenção de critérios de utilização que nos possibilitem regulá-la aos nossos interesses em determinado momento.

O entendimento das relações entre os elementos da paisagem na escala regional, é prérequisito para a intervenção na pequena escala e requer uma análise tanto funcional quanto estrutural. A compreensão da dinâmica da paisagem depende, talvez, tanto da análise dos processos anteriores que produziram os atuais padrões de uso do espaço, como de uma correta avaliação do impacto das decisões que tomamos em função de um sistema de valores ao qual estamos ligados. $O$ planejamento físico e as políticas referentes ao uso do solo, a nível regional, dependem do estabelecimento detalhado de metas e critérios de utilização do território.

Assim o geógrafo Berry ${ }^{6}$ exprime essas idéias: "Talvez a mudança social mais importante do nosso tempo seja a emergência de uma série de processos de formulação e planejamento da política para dirigir e deliberar a planificação da própria mudança, medir o curso de sua direção e modelá-la para fins determinados"

No campo do Paisagismo, Laurie ${ }^{7}$ considera que "nós estamos, atualmente, nos defrontando com problemas ambientais novos e desafiadores, de uso do solo, conservação, design de paisagens e planejamento. Uma abordagem racional para a solução desses problemas repousa tanto nas ciências biológicas, ciências da terra e princípios de conservação, como nas ciências sociais e comportamentais" A integração entre essas áreas de conhecimento e condição para a obtenção de respostas eficientes aos problemas ambientais.

Não é objetivo deste trabalho a discussão sobre o mérito das diversas posições com relação ao planejamento territorial, mas apenas abordar um tipo específico de análise geográfica e sua contribuição para o conhecimento da paisagem. 


\section{GEOSSISTEMA E PAISAGEM: A PROCURA DE PONTOS EM COMUM}

A discussão teórica que aqui apresentamos relaciona-se à escala regional e à premissa de que o estudo geossistêmico de uma paisagem (compreensão da estrutura e da dinâmica, divisão em unidades, diagnóstico e prognose) deve ser iniciado pelo estabelecimento de um ponto de contato entre os conceitos de paisagem e geossistema. Essa premissa apóia-se nas propostas de cinco geógrafos, cuja preocupação principal é a visão integrativa oferecida pelo conceito de geossistema.

Klink $^{8}$ situa a finalidade da pesquisa geossistêmica no estabelecimento de interações qualitativas e tanto quanto possível também quantitativas entre os vários componentes do sistema natural. Através do estudo da estrutura e funcionamento dos sistemas naturais, a Geografia cria a oportunidade da visão integrada da paisagem sem necessidade de estudar pormenorizadamente cada um dos seus elementos. A meta principal é o entendimento da dinâmica natural, em função da continuidade dos elementos que formam a paisagem.

Sotchava" considera que um geossistema "é uma formação natural que experimenta o impacto das decisões sociais, econômicas e tecnológicas". Considera também que, para a perfeita caracterização do geossistema, não devemos nos restringir à forma da paisagem e suas subdivisōes mas, de preferência, projetarmo-nos no estudo de sua estrutura funcional, de sua dinâmica e das conexões entre seus elementos naturais, sociais, econômicos e culturais.

A procura do ponto de contato entre os conceitos de paisagem e geossistema transparece, também, nas propostas de Bertrand, Monteiro e Tricart.

Bertrand ${ }^{10}$ considera que "paisagem é, numa determinada porção do espaço, o resultado da combinação dinâmica e, portanto instável, dos elementos físicos, biológicos e antrópicos que reagindo dialeticamente, uns sobre os outros, fazem dela um conjunto único e indissociável, em perpélua evolução"

Monteiro, enfatiza que a paisagem é "uma entidade espacial delimitada segundo um nível de resolução do pesquisador, a partir dos objetivos centrais da análise, de qualquer modo sempre resultando da integração dinâmica e, portanto, instável dos elementos do suporte da cobertura (físicos, biológicos e antrópicos) expressa em partes delimitáveis infinitamente, mas individualizadas através das relações entre elas, que organizam um todo complexo, verdadeiro conjunto solidário e único, em perpétua evolução"

Tricart " considera que, para estudar-se uma paisagem como um sistema (no caso, um geossistema), é fundamental esclarecer que paisagem não é a mesma coisa que ecossistema, porque: 
1 Paisagem é um conceito concreto, descritivo, espacializível por excelência. Uma paisagem começa mais ou menos claramente num lugar e termina $\mathrm{cm}$ outro. Sua extensão pode ser cartografada e, portanto, qualquer unidade territorial, sob esse ponto de vista, é uma paisagem.

2 - Um ecossistema é um conjunto constituído por um grupo de seres vivos de diferentes espécies e seu ambiente natural, conjunto esse estrulurado pelas interações que os seres vivos excrcem, uns sobre os outros, e que existem entre cles e seu meio. O conceito de ecossistema é carente de concretude e espacialização, porque não tem dimensão, não pode ser cartografado, não é espacial.

Argumenta o mesmo autor que, para possibilitar o contalo entre os conceitos de geossistema e paisagem, a definição mais adequada de paisagem seria "uma porção de espaço perceptível ao observador, onde se inscreve uma combinação de fatos visíveis e invisíveis e interações, das quais nós só percebemos, em um dado momento, o resultado global"

Esses enfoques geográficos da paisagem, apesar de suas estruturas formais diferentes, têm um denominador comum: as interações são as preocupações centrais dos conceitos e, portanto, seu elemento organizador. Os autores têm posições metodológicas que revelam uma convergência indisfarçável para o estudo simultâneo do formal-estrutural e do dinâmico-funcional: utilizam a abordagem adolada pela Ecologia na definição de ecossistema, tornando-a, pelo acréscimo da dimensão de cspaço, passível de ser cartografada.

Portanto, a paisagem pode ser entendida como um geossistema quando é considerada como um espaço visto e descrito através de suas características formais, estruturais e funcionais e que se altera de acordo com a variação dessas características e do impacto histórico do homem sobre ela.

Por outro lado, um geossistema tem especificidades conceituais que transparecem nas propostas de Klink, Sotchava e Tricart.

Klink ${ }^{12}$ considera o estabelecimento de qualquer limite entre duas unidades de um geossistema, um recurso puramente intelectual usado para transmitir certas informações. Isto é válido para todos os limites em todos os níveis de classificação: a estrutura dinâmica e espacial da paisagem é convertida em estrutura estática, para propósitos de representação cartográfica e a delimilação de unidades é detcrminada pela escala e pela intensão cartográfica específica. 


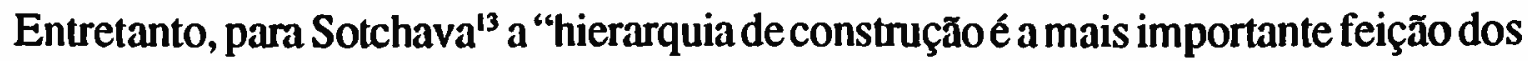
geossistemas. Devido a isso, tanto uma área elementar da superfície da terra, quanto o geossistemaplanetário ou as subdivisōes intermediárias aí existentes, representam,cada qual, separadamente ou em conjunto, uma unidade dinâmica, com uma organização geográfica a ela inerente. A organização geográfica manifesta-se num espaço que permite a distribuição de todos os componentes do geossistema, assegurando sua integridade funcional"

Fica claro, então, que um geossistema não se subdivide ilimitadamente; as unidades espaciais básicas acham-se na dependênciadireta da organizaçãogeográfica, eo mesmo autor caracteriza e delimita de maneira rigorosa essas unidades, como se pode perceber a partir da síntese que se segue:

1 - O meio natural organiza-se em hierarquias funcionais, os geossistemas, que são partes entre as quais se estabelecem relações simultâneas.

2-O desenvolvimento dos geossistemas se dá através de processos de homogeneização e diferenciação que são simultâneos e convergentes.

3 Um geossistema pode ser caracterizado, experimentalmente, pelo estudo da horizontalidade e verticalidade de sua composição, ou, visualmente, pelas relações ecológicas potenciais.

4 - Uma área homogênea, caracterizada experimentalmente, visualmente ou por suas relações ecológicas, é o ponto de partida para o entendimento do geossistema. Áreas homogêneas similares vão se combinando em unidades diferenciadas.

5 - O estudo das áreas homogêneas nos revela a estrutura do geossistema, enquanto o estudo das unidades diferenciadas nos revela a sua dinâmica.

6 - As duas categorias são, portanto, independentes e, simultaneamente, em pontos determinados, interdependentes.

Contra essa ênfase excessiva, na dualidade homogêneo/heterogêneo, Tricart ${ }^{14}$, opõe o binômio topológico/corológico. A topologia (estudo da vegetação, solos e regime hídrico) é a pesquisa das unidades homogêneas e de seus princípios de coesão. A corologia (estudo das hierarquias estabelecidas sobre uma textura de mosaico) é a pesquisa das unidades heterogêneas que podemos apreender por estudos qualitativos e estáticos.

Tricart considera, ainda, que a homogeneidade não é um conceito natural, porque não existe na natureza nenhuma formação homogênea. Os princípios de heterogeneidade 
se manifestam por um certo tipo de arranjo espacial ou de textura em mosaico. Para podermos estabelecer valores para os diferentes aspectos fisionômicos de uma paisagem, devemos conhecer a natureza das interações entre esses aspectos e a estrutura ecológica que condiciona o seu funcionamento. Para fazermos o estudo corológico de uma paisagem, devemos primeiro, determinar os elementos topológicos da paisagem. que se traduzem na sua fisionomia, estabelecer seu grau de significância e a nalureza dessa significância.

Essa posição encontra um forte apoio em Berry ${ }^{15}$ que, preocupado com a aplicação da Geografia ao processo de planejamento espacial da paisagem, consideraque "seria uma deturpação pensar na pesquisa geográlica como mera provedora de dados ou informações de finalidade sistemática... Se, de um lado, a meta da análise funcional é a organização intrínseca da entidade estudada, sua estrutura esuas propriedades, de outro lado. a abordagem comportamental da paisagem refere-se ao exame dos resultados obtidos pelo desempenho global da paisagem e às relações desses resultados com os insumos"

A enorme divergência nos métodos utilizados por esses autores, não prejudica o consenso sobre a necessidade de definir geossistema como um conjunto de unidades de estudo, baseadas ou não em dimensões. A finalidade do enfoque geossistêmico é permitir a compreensão da paisagem pela avaliação global de seu desempenho evolutivo.

No intuito de estabelecer preceitos que sirvam de diretrizes para esses estudos. Ab'Saber ${ }^{16}$, introduziu uma proposta de análise geomorfológica, com três níveis de tratamento:

1 - entendimento da compartimentação da topografia regional,assim como dacaracterização e descrição das formas de relevo de cada um dos compartimentos indicados.

2 obtenção de informações sistemáticas sobre a estrutura superlicial da paisagem, referentes a todos os compartimentos identificados, através do estudo, até certo ponto estático, das propriedadesdaspartes. Esșanáliseconduzà visualizaçãodacincmática recente da paisagem, revelando a seqüência dos processos que ocomeram em sua fonnação.

3 - compreensão global da fisiologia da paisagem através da dinâmica climática c da hidrodinâmica. O entendimento da lisiologia está apoiado no conhecimento da sucessĩo habitual do tempo, da atuação de fatos climáticos não habituais e da hidrodinâmica global da área de estudo. 
Esse conjunto de procedimentos nos permitiria avaliar a evolução ou a modificação de uma paisagem, a partir de toda a sua riqueza de solos, cobertura vegetal, relevo e interferência antrópica e propiciaria uma perspectiva de evolução para o futuro, complementando-se assim o diagnóstico com um prognóstico, base de todas as sugestões fornecidas à intervenção física na paisagem.

\section{A CRIAÇÃO DA PAISAGEM: UM PROCESSO DE ORGANIZAÇÃO DOS ELEMENTOS}

O trabalho de criação de uma paisagem, seja essa criação entendida como um desenho concebido a partir de critérios e usos, pode ser delinida como um processo de organização de elementos com uma intenção especílica: um por quê, um para quê, um parn quem.

A utilização de subsídio geográfico nesse processo de criação exige que sc evidenciem alguns pontos tomados como relerência para atingir tais objetivos:

I - a paisagem é dinâmica e de evolução constante;

2 - a paisagem resulta da combinação de processos nalurais e sociais. isto é. o homem é capaz de desencadear transformaçōes evolutivas distintas daquelas produzidas pela evolução natural;

3 - esta combinação de processos reflete-se na aparência da paisagem e é percebida, de forma global, através de diferentes canais;

4 - o ajuste dos processos é feito a partir de um sistema de valores, criação do homem, que muda no tempo e atua na paisagem, dentro de seus limites de tolerância;

5 - cada paisagem tem uma capacidade e uma adequação próprias: a capacidade, estabelecida a partir da compreensão de sua organização, reflete uma avaliação científica de sua aptidão para mudanças, enquanto a adequação se relaciona com critérios de uso estabelecidos especificamente a partir da capacidade:

6 - a paisagem tem potencialidades e restrições que, na maioria das vezes, só são percebidas a partir de situaçốes desfavoráveis (inundações, contaminações, desabamentos, desertificação, etc.); essas manifestaçõesnada mais são do que resultado de um descompasso entre a capacidade e a adequação.

Cada elemento organizador da paisagem aprescnta características próprias, possibilidades, limitações e exigências. A boa qualidade dos clementos não se traduz automa- 
ticamente em boa qualidade da paisagem. A qualidade da paisagem revela-se através da disposição adequada dos elementos vivos ou não, estálicos ou não, visíveis ou não, através da resposta intencional ao por quê, para quê, para quem.

Assim, se a essência da preocupação do Paisagismo é a busca da qualidade de interação entre os elementos da paisagem, a abordagem sistêmica que considera tanto os elementos da paisagem e suas especificidades, quanto a reunião desses elementos $\mathrm{em}$ unidades dinâmicas, tem como base a articulação operativa, a identificação e a compreensão global das relações e estratos que definem a paisagem.

Resumindo: a paisagem, considerada como geossistema, transforma-se como um todo, embora seus elementos o façam em velocidades ou em direções diversas. $O$ estudo topológico dos elementos e o estudo corológico da paisigem, permitem obter um diagnóstico de sua funcionalicłade atual.

A prognose, conjunto de hipóteses a respeito da dinâmica futura do geossistema, só deve ser formulada levando-se em consideraçãon estrulura dinâmico-funcional desse geossistema e o significado dos elementos nessi estrutura. A prognose setorial ou dos elementos nem sempre se justifica, porque não se pode estabelecer conexōes setoriais ou de elementos, sem ter presente um sistema global de valores e uma avaliação de seu impacto sobre a paișgem.

Tanto a análise geográfica, quanto a intervenção paisagística, têm por finalidade uma meta comum: a condução dos sistemas espaciais à olimização de seu desempenho evolutivo. Berry", insiste em que "a própria utilidade do planejamento orientado para o fuluro é prover uma base para a tomada de decisões mais racionais do que a adoção de simples políticas de interesses de grupos"

Ao projelarmos as imagens do futuro, impregnadas de valores pré-estabelecidos ou atribuídos a partir de estudos detalhados do presente, precisamos ser capazes de indicar as alternativas que devemos adotar ou rejeitar, assegurando que o caráler integrativo da análise geossistêmica contribua para a preservação da qualidade ambiental.

\section{NOTAS}

(1) Michael Laurie, 1978, p. 1.

(2) Brian Hacket, 1971, p. 1/4.

(3) Sylvia Crowe, 1964, p. 67/69.

(4) Ian Mcharg, 1969, p. 77/85.

(5) Vittorio Gregotti, 1972, p. 77/85.

(6) Bryan Berry, 1975, p. 1.

(7) Michael Laurie, 1978, p. VII. 
(8) Hans Jurgen Klink, 1974, p. 49/58.

(9) V. B. Sotchava, 1977, p. 2 e 9.

(10) G. Bertrand, 1972, p. 2.

(11) Jean Tricart, Paysage et Ecologie.

(12) Hans Jurgen Klink, 1974, p. 57/58.

(13) V. B. Sotchava, 1977, p. 9.

(14) Jean Tricart, op. cit.

(15) Bryan Berry, 1975, p. 2 e 6.

(16) Ab'Saber, 1969, p. 1 c 2.

(17) Bryan Berry, 1975, p. 22/23.

\section{BIBLIOGRAFIA}

AB 'SABER, Aziz N. Um Conccilo de Geomorfologia a Serviço das Pesquisas sobre o Quartenário. São Paulo: IGEOG USP, 1969, 23 p. il. (Série Geomorfologia, 18).

BERRY, Bryan J. L. Mudanças Deliberadas nos Sistemas Espaciais: Metas, Estratégicas e sua Avaliaçāo. São Paulo: IGEOG USP, 1975. 25 p. (Sćric Geografia c Plancjainento, 21)

BERTRAND, G. Paisagem e Geografia Física Global: Esboço Metodológico. São Paulo: IGEOG USP, 1972. 27 p. (Caderno de Ciências da Terra, 13).

CERI, Centre for Educational Research and Innovation, Interdisciplinarity Problems of Teaching and Research in Universities. Paris: OECD Publications, 1972, 321 p.

CLORLEY, Richard J.A Geomorfologia c a Teoria dos.Sistemas Gerais. Campinas: Notícia Geomorfológica, 1971. 22 p. Separata (21): 3-22.

CROWE, Sylvia. The Landscape of Roads. London: The Architectural Press, 1960, 136 p. il. Shapping tomorrow's landscape: preservation of existing values in landscapes and the creation of new landscapes. Amslerdam: Djambatan, 1964. Part II, p. 67 a 69.

DELPOUX, Marcel. Ecossistema c Paisagem. São Paulo: IGEOG USP, 1974, 23 p. (Série Métodos eın Questão, 7).

GALLOPIN, Gilberto C. El Concepto del ambiente humano. La Plata: Revista Ambicente, 1982. 22 p. il. Separala Ambiente, Ecologia y Desarollo, Maio 1982. (Série Temas, 13).

Ambiente y Estrategias de desarollo. La Plata: Revista Ambiente, 1982, 22 p. il. Separata Ambiente, Ecologia y Desarollo, Maio 1982. (Séric Temas, 13).

GREGOTTI, Vitorio. O território da Arquiteturra. São Paulo: Perspectiva/EDUSP, 1975. 191 p. il.

HACKET, Bryan. Landscape Planning: An introduction to theory and practice. Newcastle upon tyne, Oriel, 1971. 124 p. il.

KLINK. Hans Jurgen. Geoccologyand Natural Regionalization: Basisfor an Environmental Research. Tubingen, 1974. (Applied Sciences and Developinent, 4).

LAURIE, Michael. An Introduction to landscape architecture. Londres: Pitman Publishing Linnited, 1978.214 p. il.

MCHARG, Ian. Design with nature. London: The Oxford Press, 1969, 198 p. il. 
MEINING, D. W. The Beholding Eye: Ten Version of the Same Scene. Louisville: Landscape Architecture, 1976.65 p. il. p. 47/54, janeiro, 1976.

MONTEIRO, Carlos Augusto F. Derivações Antropogênicas dos Geossisteınas Territoriais no Brasil e Alterações Climáticas: Perspectivas urbanas e agrárias no problema da elaboração de modelo de avaliação. In: Anais do Simpósio sobre a Commidade Vegetal como Unidade Biológica, Turística e Econômica. São Paulo: ACIESP, 1978. 248 p. il.

MOTTA, Flávio L. Roberto Burle Marx e a nova visão da Paisagem. São Paulo: IGEOG USP, 1977. $35 \mathrm{p}$.

OREA, Doiningos Gomez. El Medio Físico y la Planificación. Madrid: CIFCA, 1978. 144 p. il. Vol. 1.

SIMONDS, Jolm O. Landscape Architecure: An Ecological Aproach to Environmental Plamning. New York: McGraw Hill, 1961, 244 p. il.

SOTCHAVA, V. B. Por ıma Teoria de Classificaşão de Geossistemas de Vida Terrestıe. São Paulo: Departamento de Geografia da FFLCHUSP, 1972. 20 p.

O Estudo dos Geossistcmas. São Paulo: IGEOGUSP, 1977. 52 p. (Série Métodos em Questão, 16)

STEINITZ, C. Defensible Processes for Regional Landscape Design. Louisville: Landscape Architecture Technical Information Series, 1979. p. 1-31. Maio 1979.

SUKACEV, W. N. The Relationship Betwee'n the Terms Geographical Landscape and Biogeocenosis. Tubinghen, 1972. (Applied Sciences and Development 2)

TANSLEY, A. D. The use and abuse of vegetational concepts and terms. Ecology. 1935 (16) p. 254-307.

TRICART, J. L. F. Paysage et Ecologic. 1980. 